Flavour

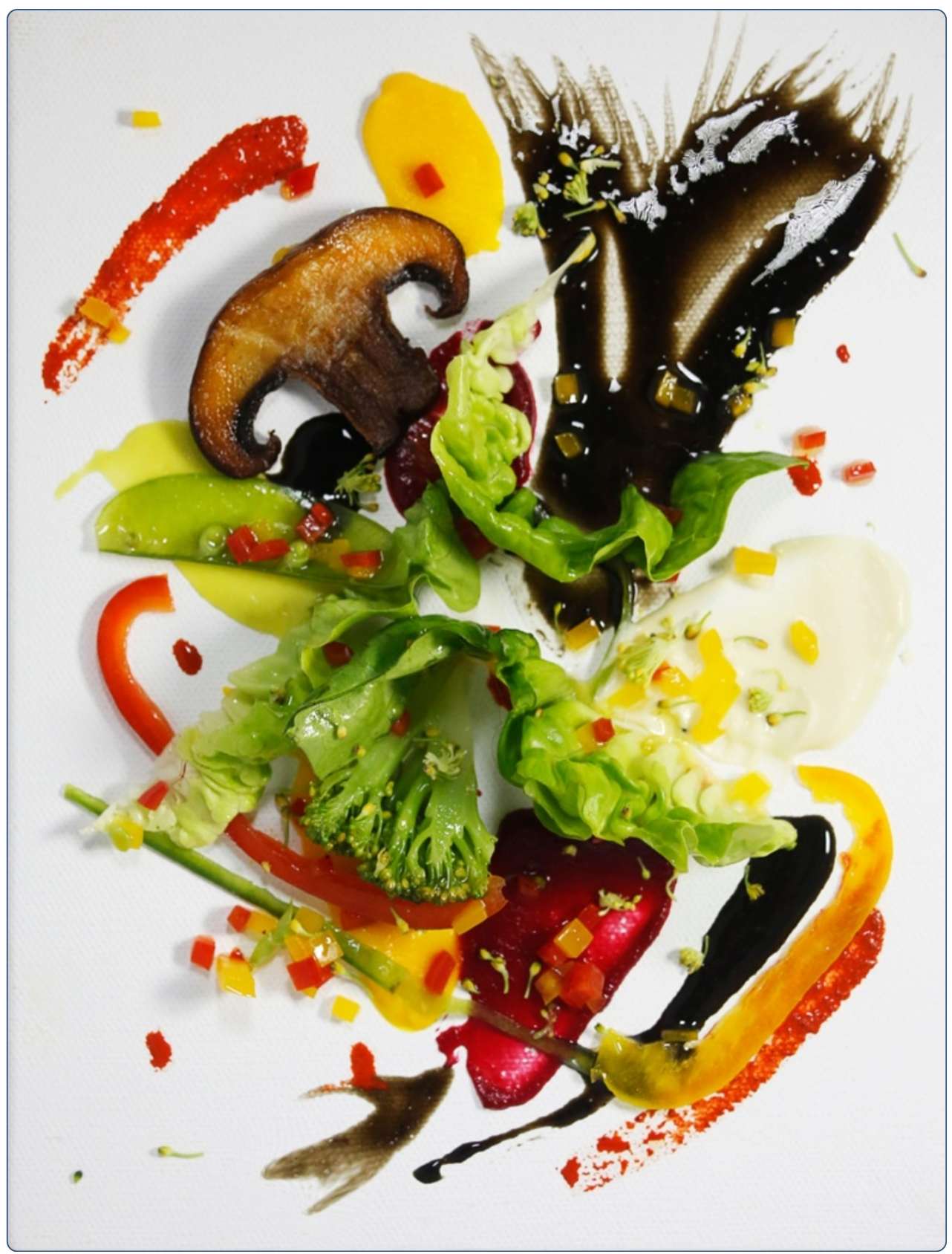

The plating manifesto (I): from decoration to creation

Deroy et al. 


\title{
The plating manifesto (I): from decoration to creation
}

\author{
Ophelia Deroy $^{1 *}$, Charles Michel ${ }^{2}$, Betina Piqueras-Fiszman ${ }^{2}$ and Charles Spence ${ }^{2}$
}

\begin{abstract}
At a time when a growing number of chefs and innovative food industries are starting to set up their own research kitchens and work with renowned scientists, it is surprising to see that issues related to the visual presentation of food on the plate are being left out of these successful exchanges. The variety of presentations created by chefs, and the number of varieties of tableware now available to achieve them, represent a formidable opportunity for cognitive scientists to study the more complex effects of vision on food experiences, which certainly should not be missed. Chefs can also benefit from the new insights that a scientific approach can bring to these areas, which previously have often been left to intuition. In this manifesto, we claim that this transfer of knowledge represents much more than merely another addition to the art and science of cuisine: it is its essential completion, as gastronomy moves more and more toward the ideal of a total multisensory art, as captivating for the eye as it is for the palate. Before turning to the scientific recommendations and review in the second part of our manifesto, we want to promote a different approach to plating, which breaks with the more functional and decorative purposes of plate ware, and puts experiments in visual presentation at the heart of modernist culinary expression.
\end{abstract}

Keywords: Aesthetics, Culinary arts, Food, Multisensory art, Plating, Plate ware, Presentation

\section{Introduction}

'The first taste is always with the eyes.' [1]

'The visual sensation of a dish is as important as its flavour.' [2]

'I think we're going to need designers that think about food and design in ways that we've never thought about before.' [3]

In everyday experience, food is never presented or served in isolation: it always comes in a container - in a bowl, on a plate, or in a disposable pack, as is typically the case with foods eaten directly from their packaging [4]. With plates comes the idea that food should be presented in the most attractive manner possible, and that presentation, from the choice of the plate itself to the complex spatial arrangement of colours and ingredients

\footnotetext{
* Correspondence: ophelia.deroy@sas.ac.uk

${ }^{1}$ Centre for the Study of the Senses, School of Advanced Study, Institute of Philosophy, University of London, Malet Street, WC1E 7HU London, UK
} Full list of author information is available at the end of the article on the plate, matters to the final reception of a dish by the diner.

This perhaps obvious fact, what we call 'plating', has received surprisingly little attention up until now from scientists interested in food or eating experiences. Nowhere is the topic of plating mentioned, for instance, in the collection devoted to the dimensions of the meal edited by Meiselman in 2000 [5]. The 'five-aspect meal model' proposed by Gustafsson [6] ignores it totally. This neglect contrasts with the huge interest shared by chefs, the public and the media alike for photographs of gorgeous or adventurous plating, as evidenced by the thousands of pictures exchanged via social media, and the emergence of specialized magazines, such as The Art of Plating [7] (see Figure 1).

If diners and the media don't need to be convinced of the importance of plating, why aren't scientists and chefs more interested in understanding what makes these plates so attention-grabbing and how they affect the diner's experience? Everyone should be especially aware that food presentations are likely to bear on all three key components of pleasure, as identified by Daniel Kahneman 


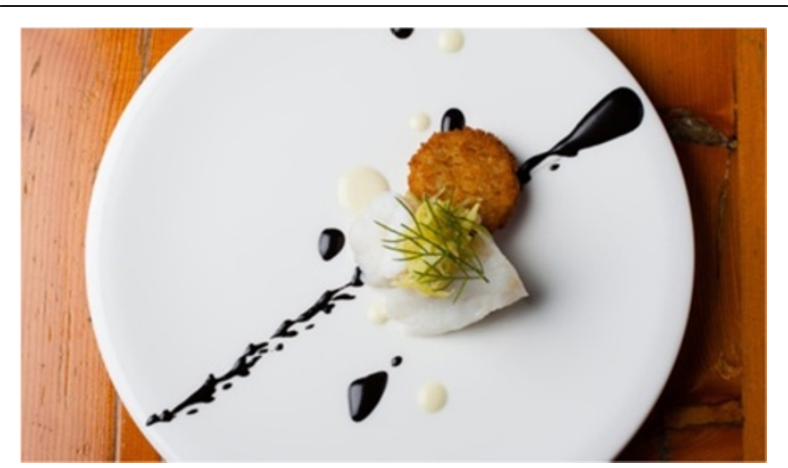

Figure 1 Example of plating shared through 'Instagram' networking service by @theartofplating.

in his work on hedonic psychology $[8,9]$ : the pleasures of expectation, experience and memory. The point of this manifesto is to convince both chefs and scientists alike that they ought to be working together much more closely on the effects of aesthetic food presentations, and that there are rewards to be won on both sides from adopting a more scientific approach to plating. It is, though, to be expected that both camps might be difficult to convince: isn't great plating a matter for individual talent and creativity, which does not afford scientific generalisation? What would science add to plating? Isn't visual presentation somehow extrinsic to flavour perception, and hence something that rightly belongs more to the social ritual of the meal than to food science?

We think that these two concerns should be addressed together. What is required is first and foremost a different way to look at plating: one that shows why food presentation is integral to our eating experiences, and therefore to the sciences that want to understand them. In the second part of the manifesto, we hope to show why, and how, the step between existing scientific studies of the visual aspects of food (see $[10,11]$ for a review), should be extended to include complex plating. Before that, though, we believe it is crucial to revisit the status of aesthetic food presentation: plating should not be seen merely as decoration, but as an integral part of the multisensory eating experience. Many consider plating only as the cherry on the cake of cooking, as the intuitive final step in the process of creating a dish that could be executed and planned independently of the flavour of the dish itself. This view is too limited by far, as we argue in this first part of the manifesto: plating has become central to the eating experience, and should now be recognized both as a drive to the culinary creation and central to the reception of a dish.

Plating has not always been so central, of course. In the next section, we explain how this change has occurred, and illustrate how and when the plate stopped being a merely convenient container and a decorative frame for the plate to become the canvas on which chefs can express themselves. Then we show why a plate can be more than a canvas, and why innovation in terms of flavour and presentation can be seen as going hand in hand. The increasing variety and originality introduced to multisensory food presentations and plate ware marks not only a new step in the history of the progressive aesthetization of our food experiences [12-14], but also a growing importance of visual elements in eating experiences and a blurring of the boundaries between the edible and the non-edible. This larger history, we believe, should be heeded by chefs, industrial food concerns and food specialists across the sciences and other disciplines.

\section{Stop considering plating as mere decoration}

The rituals and traditions surrounding the presentation and serving of foods have usually been topics of study for cultural historians, anthropologists and ethnologists $[15,16]$. The symbolic and historical aspects of food presentation are certainly not subjects that scientists and chefs should ignore when they want to understand how the experience of a dish can be modulated by plating. Some aspects of food presentation, though, make it a domain for experimental psychologists to study in the laboratory, and not just the chasse gardée of observational human sciences: With the progressive individualization and experimentation currently introduced by chefs and designers to the presentation of food comes the possibility of understanding the principles of harmony, balance and attraction that make some of these attempts more successful than others. If, as the popular expression goes, we 'eat with our eyes', then the visual presentation of food $[10,11]$ may also turn out to be almost as rich and important as the sensory qualities of the food itself in terms of determining the expectations, experience and memory of a dish. So, if there is so much more nowadays to effective plating than merely garnishing a dish with a sprig of fresh parsley, the first thing to reflect upon is how, or why, the trend has changed from simply adding that garnish through to thinking of patisserie as architecture, or even to trompe-l'oeil dishes masked as the centrepiece of the table at Noma; currently one of the world's top restaurants.

The assumption that plating and plate ware belong merely to social refinement or the decorative arts is deeply rooted in our everyday practice. Rules of plating have for a long time only appeared as part of the domestic etiquette; museums hosting the majority of the collections of precious plates, jugs and serving pots around the world most often stand apart from the classical visual arts, such as paintings and sculpture, which are granted an aesthetic value. The status of decorative art is certainly ambivalent: as ironically underlined by artist Grayson Perry in his recent (2013) Reith Lectures, 
pottery isn't a respectable art. The fact is that decorative arts retain a utility and this is obviously true of plates, which undoubtedly have their uses in terms of containing and serving food.

The term 'arts' suggests, however, that the decorative arts contribute something more than utility: they are also there to celebrate the value of the cultural practice for which they are used. In this respect, decorative plate ware constitutes a frame, highlighting the food and its consumption. The arrangement of food itself on these plates can also be granted a decorative dimension, as shown by the Japanese art of Kaiseki. The century-old tradition of Kaiseki is a delicate and skilful ceremony, and the closest and earliest instance of plating as an art [17]. Chefs carefully select their vessels, utensils, and other inedible garnishes so as to ensure that each dish complements the food that is going to be served from it (see Figure 2). The aim is to create a connection with nature and, because of this, the type of adornment changes according to the season and the foods being served. The physical properties of the plates also change in order to reflect the connection between the food and the seasons, with icy plates being served in summer, and warm dishes in winter. The chefs working within the constraints of this style of cuisine try to enhance the visual appearance of the dish as much as possible and show an early example in which the use of precise culinary techniques is considered in connection with the rituals surrounding food presentation.

Japanese culture certainly had a huge influence on today's gastronomy, and the best way to understand this is to stress the contrast with what existed before it impacted Western cultures. In fact, plate ware and plating had a merely functional importance in the West. In the Middle Ages, serving meals basically involved ladling stews or porridge into hollowed-out 'plates' that had been cut from loaves of old bread. In this case, the

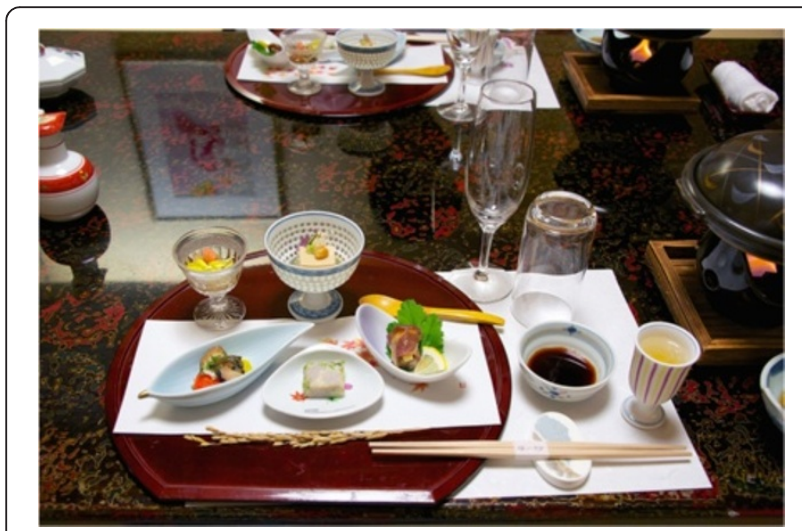

Figure 2 Kaiseki cuisine (picture free of rights; shutterstock_115520557). staler the loaf, the better [18]. Turning to royalty, one can find much more elaborate, heavily meat-based, feasts with all sorts of garnishes, sauces and fruits piled on large plates or trays. French researchers have documented old cookery books and drawings showing that the presentation of the food could be very important in such medieval settings but mostly as a way to distract the diner's attention from the lack of any great refinement in the flavours of the foods themselves. The search for colour was prioritized over flavour: Yellow (gold and saffron) and green (a high ranking colour on coats of arms) would have been used to demonstrate social distinction. Some cooks would try to make the animals that they served look like they were still alive, often retaining the animal's fur or feathers for this very purpose. Gold leaf might be used to decorate the animals for the king and members of the royal court. Rare ingredients were important, and had to be seen in abundance, showing that plating was meant to serve as a celebration of the host's power, more than a celebration of the food itself [19].

The seventeenth and eighteenth centuries are said to have marked a change in French cuisine, initiating the first steps toward 'haute cuisine', which so many of us are familiar with today. Louis XIV placed cuisine as an integral part of French culture, for both its flavour and its aesthetic appeal. With Antonin Carême, the celebrated French chef, came an important change [20]. Carême was an avid amateur student of architecture and chef to distinguished figures all the way up to Napoleon Bonaparte and Tsar Alexander. He became famous, in part, because he often presented his culinary creations using architectural concepts, building his dishes up into the shapes of famous monuments, waterfalls and pyramids (e.g., see Figure 3). Carême, who was sometimes referred to as 'the king of cooks and the cook of kings', is thought to have invented the famous croquembouche (French for

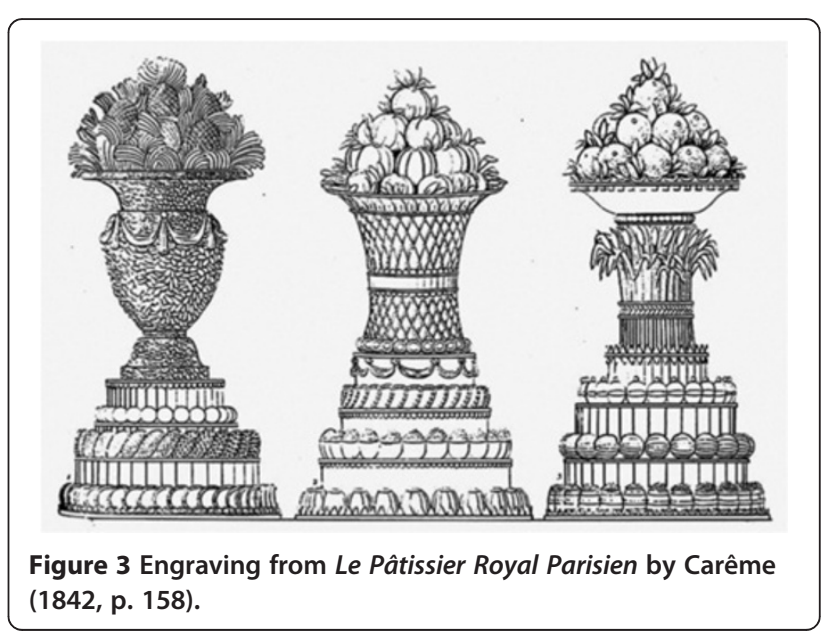


'crunch in mouth'): This dessert, made with custard-filled (or cream) puffs coated with caramel and stacked in the shape of a towering pyramid, is even now a masterpiece in important celebrations, such as weddings and baptisms (see Figure 3).

In our sense, though, the main impact of Carême comes from his introduction of two conceptual innovations, which would later amalgamate with the Japanese tradition and elevate contemporary food presentation to new heights. The first new idea infused by Carême into food presentation was one of originality. Chefs, like architects, could select and compose food presentations according to their own individual inspiration, and not simply according to pre-existing codes, as in the case of Kaiseki cuisine. This rupture with traditional codes was a real liberation for new forms of plating, and still continues today. The second idea that can be credited to Carême, perhaps more important, is the idea that plating could be arbitrary. The presentation of a dish no longer needed to be linked to the ingredients that were used in its making; to be shaped like the animal or refer to the season. It could refer to other arts, and invent its own aesthetic forms. With these two crucial ideas, the art of food presentation became autonomous. It also became an integral means, by which a chef could impress his guests.

This evolution has been slow: Carême's innovations in the art of food presentation only gradually spread into culinary culture. Their diffusion, though, has been accompanied, and probably affected, by other changes. The progressive introduction, during the course of the nineteenth century, of the 'service à la Russe', meant that foods would come one after another in individual servings, and that guests were no longer in charge of serving themselves what they craved (this was 'service à la Française', which became what we now know as a 'buffet'). This change had a lasting impact. Nowadays, a restaurant dinner often means a succession of small plates and a paraphernalia of different types of glass and cutlery. However, as diners needed to eat faster and lighter, without sacrificing the flavour qualities of the foods, the 'service a la Russe' also had to become more rational. Escoffier, the father of modern restaurants, understood this before others; as he wrote in the 1907 preface of his Guide Culinaire, considered by many cooks to be the bible of cuisine, 'the clients, requiring to be served quickly, give us no alternative but satisfying them, or losing them' [21]. The solution offered by Escoffier was to rationalise preparation in the kitchen, with the unfortunate consequence of separating the cooking brigade from the plating brigade.

One has probably to wait for what is known as 'nouvelle cuisine' to see things come together: The Japanese influence on French chefs, trained to revere Carême and Escoffier, transformed the culinary landscape. This history might be well known by some, but it has not sufficiently been understood as explaining the centrality of plating in today's culture. Early in the twentieth century, Fernand Point introduced elements that would later become hallmarks of nouvelle cuisine: seasonal ingredients with a focus on natural flavours, and above all, simplicity and elegance on the plate. Point's style was consolidated by his most famous protégé, Paul Bocuse, whose neat and detailed presentation of food soon provided some of the most iconic images of the increasingly popular nouvelle cuisine movement in the 1960s and 1970s [22]. Several chefs of that period confessed to the profound influence that Asian cuisine (Japanese, in particular), had on their approach to the products and to presenting food. In his book, Raymond Oliver, one of the first star chefs to appear on television, affirmed that in cuisine, as in art, he was a partisan of 'the sobriety of lines and the richness of matter' [23]. The opening of the first French culinary school in Japan in 1960, by chef Shizuo Tsuji, resulted in a much greater cultural exchange between leading Japanese and French chefs, including Paul Bocuse and Alain Chapel. The Troisgros brothers (Jean and Pierre) are known for their art of 'plate dressing, which became popular amongst chefs and restaurateurs. The different elements of the dish were arranged on round plates, seeking symmetry, height and technical performance. More recently, Michel Troisgros and Michel Bras have also acknowledged the influence of Japanese ideas on their cuisine. Although Troisgros was more inspired by the Japanese approach to taste and flavours, Michel Bras, whose second passion is photography, clearly drew from the Japanese style in terms of the visual composition of his dishes, creating landscapes of food on the plate (Figure 4).

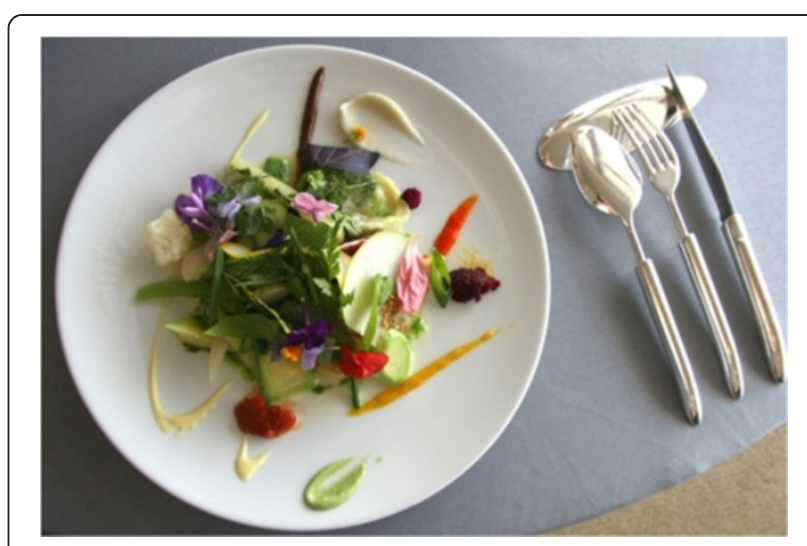

Figure 4 Gargouillou of Young Vegetables, Michel Bras.

(Reproduced by permission of Palis-Trébosc, from Bras: Laguiole, Aubrac, France, éditions du Rouergue). 
'The Gargouillou is a model: made of the seasonal products of a particular land, he gives back in its composition the shape and spirit of the landscape.' [24]

As plating became more artistic, in the French interpretation of the Japanese style, it is important in our eyes to see the mark of Carême's inheritance: plating has become original and arbitrary, and not rigid and linked strictly to the ingredients. With nouvelle cuisine, chefs officially proclaimed their creative independence, an evolution achieved over many centuries in refining the art of cooking. We want, however, to stress how this change has led to another one, where the plate is not just the canvas on which the chefs can express their creativity, skill and style ${ }^{\mathrm{a}}$.

\section{When plating becomes integral to cooking and eating}

The change initiated by the nouvelle cuisine movement should not be underestimated. It has marked a radical departure, from basic presentation to a novel concern for the look of plates and food. Another radical change is, however, taking place nowadays. In the 'nouvelle cuisine' approach, plating is still considered as extrinsic to culinary creation. It tends to be an additional element, whereby the diners are able to admire the effort put into every single plate of food. Diners are each noticeably intended to be served an exact copy of the original creation that the chef wanted them to enjoy. Indeed, it is presumably no coincidence that it is around the peak of the nouvelle cuisine movement that chefs started to add their monograms to the plate ware.

The nouvelle cuisine style of plating reaches its zenith with the approach championed by such chefs as Alain Ducasse and Pierre Gagnaire, both stars of the contemporary culinary scene. The next generation of international chefs, led by the likes of Ferran Adrià in Spain, and Grant Achatz in Chicago, amongst others, have taken minimalism in cooking and presentation even further, but also introduced a key difference ${ }^{\mathrm{b}}$. In molecular gastronomy (or modernist cuisine, as it is sometimes called), the creation of new flavours and invention of new presentation styles go hand in hand. These two elements, which were previously considered distinct, are now interlaced in the process of culinary creation. Molecular cuisine, to put it simply, is a set of technologies and ingredients used to produce a new style of high-end dining presentation. Technologies from chemical laboratories and texture agents borrowed from the food industry have given wings to the imagination of chefs, to 'hack' the visual appearance of preparations in ways that are totally novel.
Through this new technique, food can be abstracted from its original form, giving rise to previously unexplored shapes and textures such as the now all too famous foams, gels and spherifications [25]. This approach is definitely also liberating originality, giving rise to a new form of artistic performance or experience design, with the potential to play with everyone's imagination, to trick human expectations as well as the diner's senses [26]. Presentation is a hidden force, guiding the process of culinary innovation. As such, it has begun to impact the expectations, experiences and memories of the diners, and is progressively building new habits and culture beyond the high-end restaurants, in supermarkets, fine grocery shops and home cooking.

The principles that are stated next are not just surprising creations to have emanated from the world's most innovative restaurants. They are also an avant-garde where the new generations of chefs and diners set their new standards.

\section{Plating can create new flavours}

As an outcome of molecular gastronomy, often both the meal and the means of presentation interact when planning a dish. As noted by Rasmus Kofoed in a recent interview:

'I have a clear idea of how the plates should look and taste. You have a starting point and then you develop it further and constantly optimize it; in terms of the visual presentation so you can reveal the secret of each ingredient in its purest form with excellent flavour and in harmony with the others.' (Rasmus Kofoed, The World's Finest Chef 2011) [27]

Thinking about new visual arrangements certainly has the potential to inspire new culinary creations, as reflected by Pierre Gagnaire:

'I need to put some poetry in my plates. The presentation of a dish teaches me new rules of harmony and through this exercise, I find a form of peace. I always have to position my cuisine visually. In this I am guided by my instinct, which helps me perceive qualities and flaws and from time to time, reveals new flavours to me.' [28]

The way in which the elements on a dish can be arranged may, in fact, lead them to have different flavours (physically, as opposed to any effect caused by the psychological impact the different display can have). The expectations raised by the visual appearance of the plate also play a tremendous role in shaping the experience of the diner, including orienting behaviour: 
'You have to construct the dish so the client can instinctively know where to start. Michel Troisgros used to call it the tale. The dish must tell a tale. The dinner must know where to start and where to arrive in order to perceive all the right flavours. Just like when you read a canvas.' (Florent Boivin, former sous-chef at the Troisgros restaurant, personal communication)

What one should recognize here is that the overall presentation, and the surprises or delights that accompany it, is where the talents of the chefs are really focused, along, of course, with the sourcing of ingredients and their preparation.

Use plating to enhance the uniqueness of the experience Currently, there is something of a trend toward a more product-oriented approach, together with a respect for the nature of the ingredients, and a tendency for the tableside service to become much more theatrical in nature. The finest of ingredients, produced by committed farmers, are not just cooked but interpreted by chefs and emerging culinary artists. Though the insistence is on seasonality, as in the Japanese style, uniqueness is really what is at the centre, and extends from plating to products themselves. This direction shows how the concept of originality first applied to presentation is now transforming culinary preparation and foods themselves. Products are now uniquely sourced or even specifically designed in the backstage kitchen; foods that only belong to the here and now of the restaurant experience, as with artists preparing their own pigments. Some of the dishes are carefully designed so as to display and enhance the ingredients or to show off the cooking procedure that has been used. Plating (or staging) the food is a way to play on a diner's expectations, experience and memory: The food must be presented in the best possible way, while at the same time delivering a memorable dining experience.

With these new trends, we are entering a new revolution. Instead of being a chef's signature, reproducible from plate to plate, as on canvases, the visual presentation of a dish is now supposed to be as unique as the food itself. More specifically, plating and presentation are used more and more as a way to stress, not just the chef's culinary artistry, but the uniqueness of the experience that is being performed in front of the diner. They now form one of the multisensory keys that the chefs and staff in prestigious restaurants can use in what can be considered a new form of performance art, the staging and orchestrating of culinary experiences.

Sometimes, the creative team, which may often involve the chef and maitre d'hôtel together with part of their respective teams, together with an invited designer, may actually commission a unique creation that can only be used for a specific course. The higgledy-piggledy tiered sandwich stand of Heston's Mad Hatter Tea Party dish, served at The Fat Duck restaurant (Figure 5), was designed in collaboration with Reiko Kaneko [29], in response to a design brief from the culinary team at The Fat Duck. Meanwhile, at Eleven Madison Park in New York, chef Daniel Humm uses a tailor-made set of plate ware to serve his clam-chowder [30]. The elBulli restaurant in Spain used to be famous for closing for almost 6 months a year, time that the creative team would use to attend specialized courses, gather new ingredients and equipment, travel to different continents and cooperate with other industries.

Grant Achatz, Alinea's chef, has an on-going collaboration with Crucial Detail, a multidisciplinary design group [31], to present the creations in unique and impressive ways. To serve a dehydrated translucent piece of bacon wrapped in butterscotch and apple leather, Achatz decided to hang it from a bow, in a way that accentuates the lightness and translucency of the components in the dish (see Figure 6). This creation points toward another trend that we expect to grow; where the plate itself disappears in the background of the performance, or even disappears totally to heighten the theatrical and active aspect of food delivery.

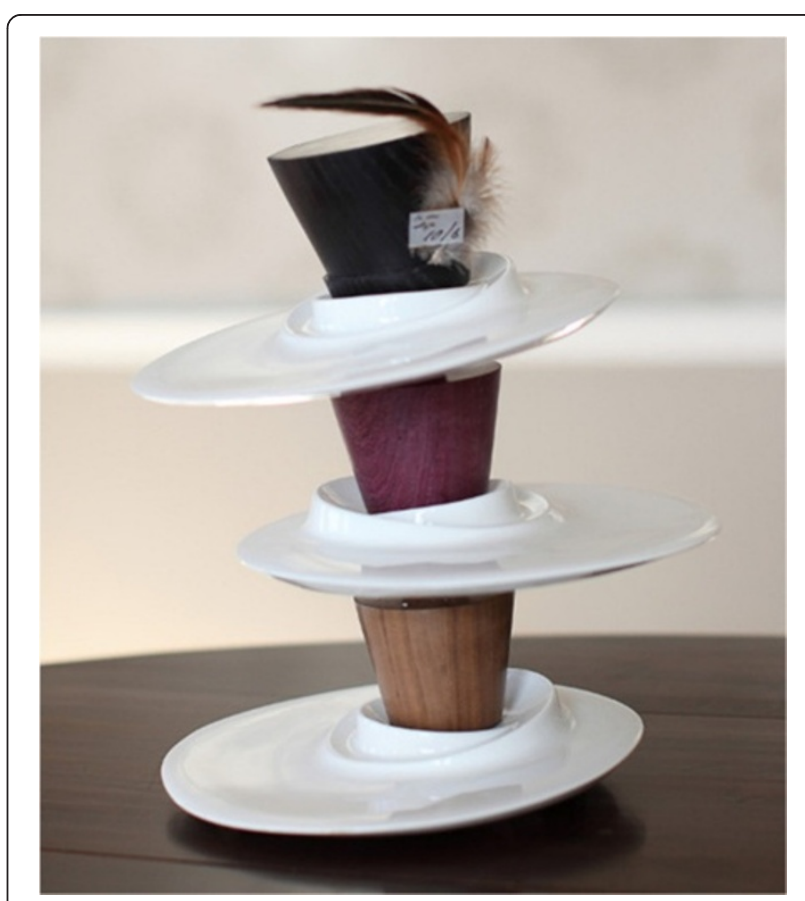

Figure 5 Heston Blumenthal's Mad Hatter's Tea Party plate ware, designed especially for the course served at The Fat Duck by Reiko Kaneko. (Reproduced by permission of Reiko Kaneko). 


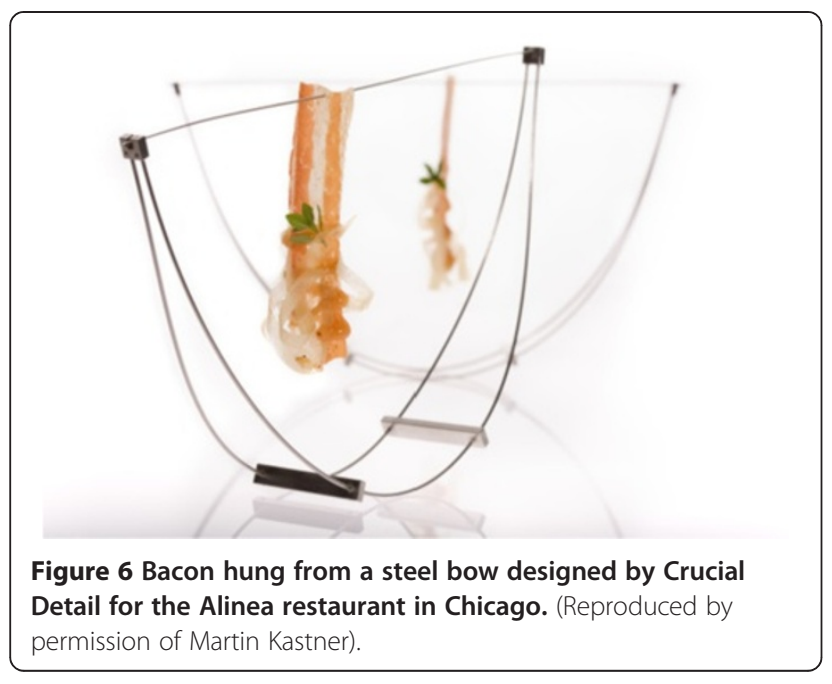

Let plating 'hack' the other arts

An incredibly wide range of plate ware, bricks, black slate, and any unconventional or reclaimed objects are now welcome on the table; as a homage to the readymade in art. Innovative chefs, striving to present their dishes in the most uncommon and memorable of ways (while also telling a story), are using any kind of material on which it feels right to place food. Take, for instance, the chicken liver parfait that came on a caramel-glazed red house brick, served in a London restaurant in 2012 [32]. Other natural options are also increasingly being used, such as slices of tree trunk, hay or plant leaves. The involvement of natural materials in the presentation of the dish may be designed to release an aroma; but at the same time, one imagines, such naturally congruent plate ware is meant to intensify the freshness of the ingredients, maybe suggesting some additional information on the dish.

Interestingly, gastronomy then seems to repeat the artistic movements that have marked the visual arts; here ready-made, there with explicit references to their unisensory painted predecessors. This referential dimension is important when revisiting the status of gastronomy as an art, as some want to see it as a characteristic of artistic creation [33]. Returning to Chicago's Alinea restaurant, the most conventional utensils (cutlery) are unconventionally used to place the food. In a dish that goes by the name of Squab, no plates or similar receptacles are to be seen. The waiters simply bring a set of nine forks and spoons, each containing morsels of different foods, and then arrange the cutlery in an apparently random manner (a different arrangement for each diner). This dish is inspired by Miró's Still Life with an Old Shoe (1937). Although the actual painting isn't shown during the course of the meal, on looking it up afterwards, one can see some similarity with the painting (Figure 7).

Michel Troisgros, a self-confessed lover of contemporary art, recognized one of Mondrian's classic paintings in one of the culinary creations that he and his team were working on, a few days after visiting an art exhibition dedicated to the painter in 2010 [34]. He went on to name this dish Lacquered mullet façon Mondrian (Figure 8). Another of his creations, White Milk and Black Truffle Dish (Figure 9A), consists, at first sight, of a white surface on a white plate. The waiter slashes the immaculate surface with a knife in front of the client, unveiling the black matter lying underneath. Michel Troisgros confessed that it unintentionally brought him to Fontana's lacerations (Figure 9B).

'I made a Lucio Fontana without even noticing. The link to artworks emerges from the subconscious, it remains infused in me.' [34]

Other chefs find their inspiration in performance art, surrealistic incongruity and trompe-l'oeil. At Noma, for instance, the diners are told by the waiter that their first two courses are already on the table. This all seems very strange, as there is nothing on the table. Well, nothing, apart from a collection of plant pots in the centre (the clue being given by the fact that there are exactly as many flowerpots as there are diners at the table). The

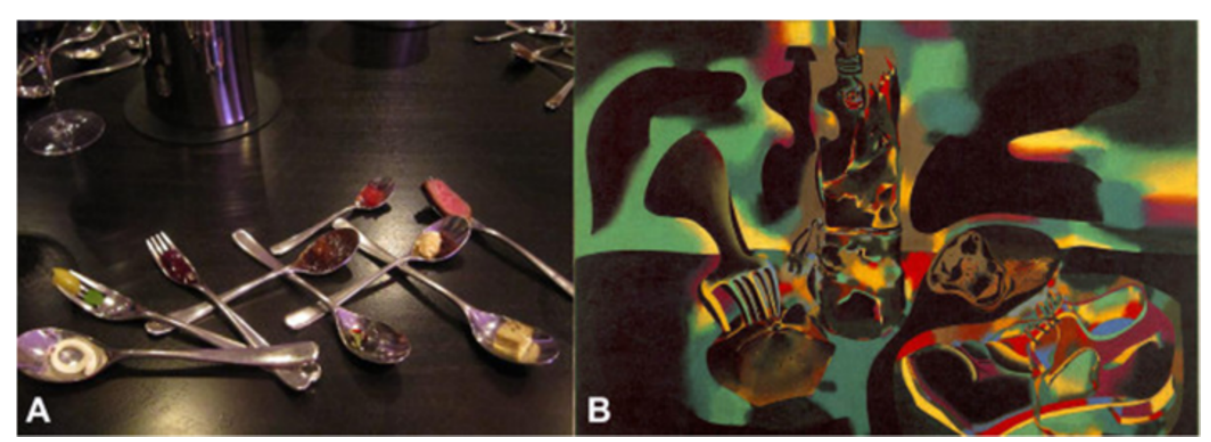

Figure 7 Inspiration from art. (A) Alinea's Squab, a Miró-inspired dish consisting of a total of nine spoons and forks (reproduced by permission of Mijune Pak). (B) Still Life with an Old Shoe, Miró, 1937. 


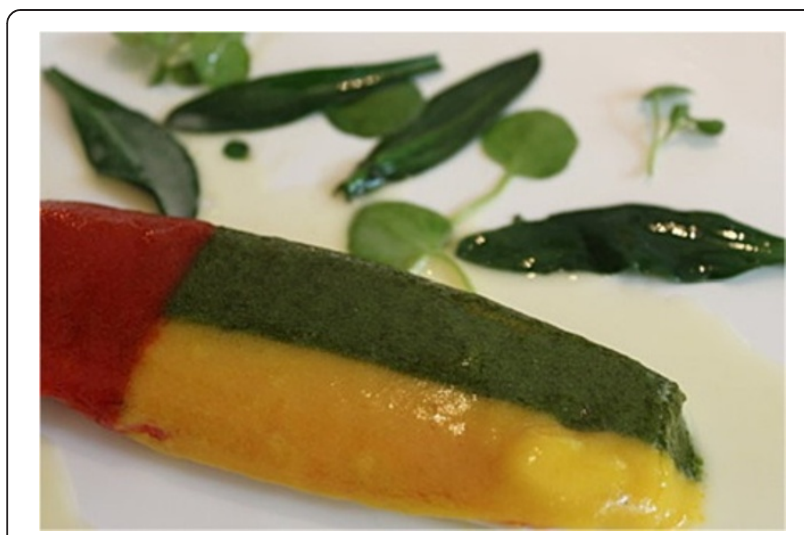

Figure 8 Michel Troisgros' Lacquered mullet façon Mondrian (reproduced by permission of Marjorie Fenestre) inspired by one of Piet Mondrian's compositions from the 1920s and the 1930 s.

diners are expected to bring the pots closer and start digging in using nothing other than their hands, literally, into the 'soil', eating everything they find, including the roots. This starter, camouflaged as it is in a terracotta flower pot, consists of carrots and radishes planted in a dark brown, crunchy edible mixture of malt and hazelnut flour (which gives a pretty good visual impression of soil) with a greenish yoghurt-based sauce lying at the very bottom (Figure 10). This example, in our sense, leads to the last change introduced by the new art of plating.

\section{Blur the frontiers between what is edible and what isn't}

In another of the high-end tables of the Michelin-starred restaurants, Andoni Luis Aduriz has developed a novel coating technique through a process of creative experimentation at the research and development kitchen of his restaurant, Mugaritz. The aim here was to create a visual copy of an Andean tunta (a traditional dried potato), which looks much like a stone [35] (Figure 11). This experimental approach to culinary creation 'reveals a new culinary category that creates an object that retains the same sensory qualities of the potato, but with the outward aspect of a stone gathered from a river bed'. The design of its tactile properties 'stony feel, dry, and clean to the touch' suggests that it is to be eaten with hands, perhaps adding to the experience of eating.

There will be occasions where the plate ware itself may be conspicuous by its very absence, that is, the food is served directly onto the table itself. At Alinea, a number of the desserts require a performance that can last for several minutes. First, the waiters lay a waterproof tablecloth over the table. They then bring all sorts of small ramekins and bowls with sauces and other ingredients with different textures. Next, one of the chefs emerges from the kitchen, and, in front of the intrigued diners, will start 'plating the table'. That is, they will start breaking solid elements, painting with liquids (both drop-by-drop and by splashing), and spreading powders, with all the aesthetic skill, delicacy and control that only the best artists have. No doubt about it, this dessert has been designed to challenge the conventions of how food can be served and eaten (Figure 12).

\section{Turn to the science of plating}

As philosopher, designer, chef and scientist, we consider that the long history of plating, and the new trends we have described, is calling for a novel investigation into the aesthetic of food presentation. We are especially interested in the potential this new area offers for synergistic collaboration between the kitchen and the laboratory. Collaborations between cognitive scientists interested in multisensory perception and chefs interested in enhancing the diners' experience have already successfully led to the creation of new dishes, and to a better understanding of the multiple factors bearing on a single mouthful [36,37]. With plating and food

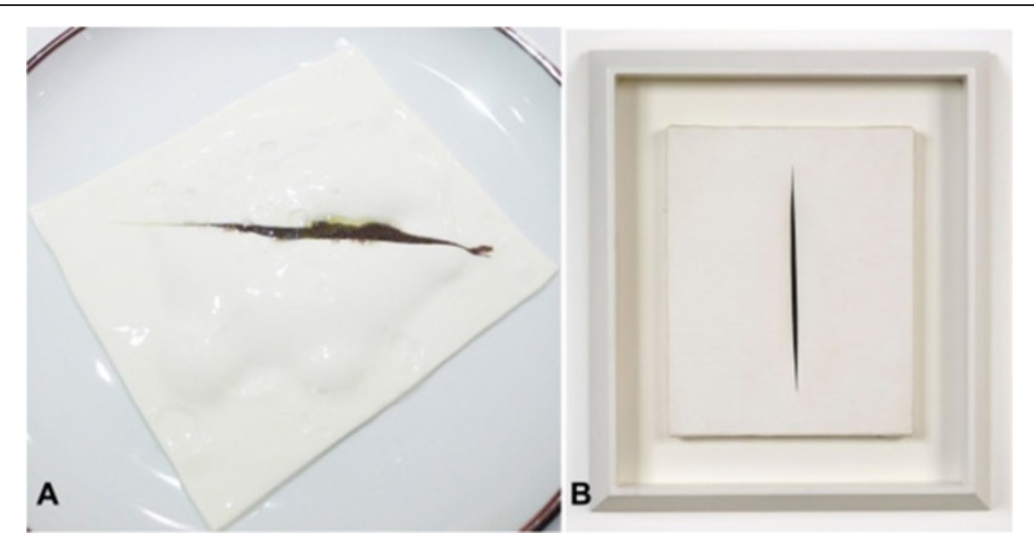

Figure 9 The connection with art. (A) Milk White and Black Truffle Dish (reproduced by permission of Bruno Verjus). (B) Concetto Spaziale, Attesa. Spatial Concept, Expectation, by Lucio Fontana, 1966. 


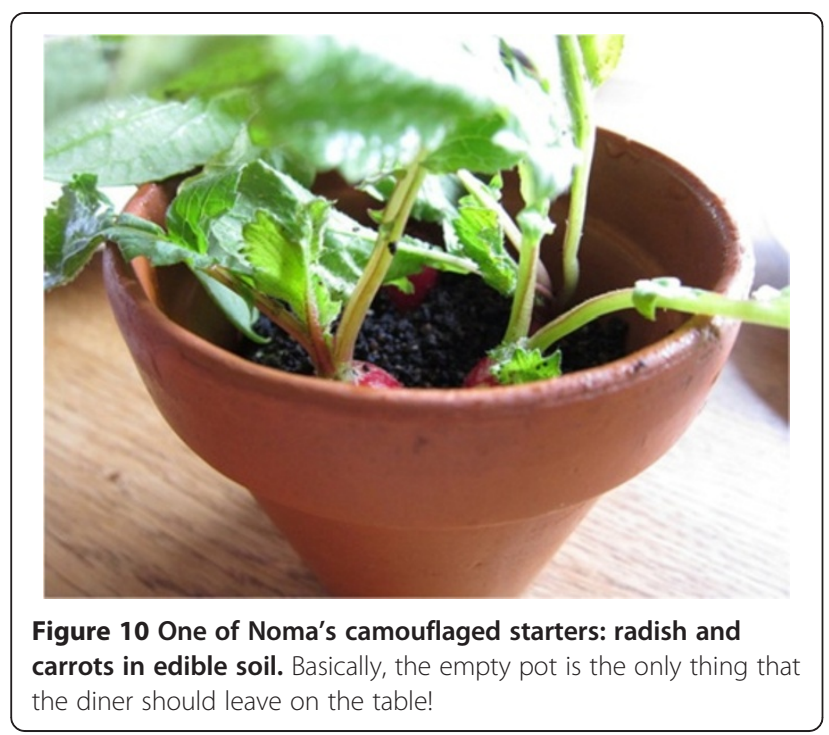

presentation, the benefits of the collaboration could extend not just to the experience itself, but also to the expectations generated by the sight of a complex plate, or the memory of eating its contents.

However closely related the quests for new flavours and novel presentations are, there is still a division of methods that remains surprisingly dominant, and which it is our goal to remedy. Chefs, or the innovative industries, have tended to blend their art with science in order to create new techniques and flavours, or to improve on existing ones; but they keep relying merely on their intuition when it comes to the visual presentation of foods, neglecting the science emerging behind this side of culinary creation.

Seven years have passed since Ferran Adria of elBullifoundation, Heston Blumenthal of The Fat Duck, Thomas Keller of the French Laundry and Per Se, and the writer Harold McGee predicted, 'Preparing and serving food could therefore be the most complex and comprehensive of the performing arts,' [38] and in many ways, their prophecy is unfolding right now in traditional and pop-up

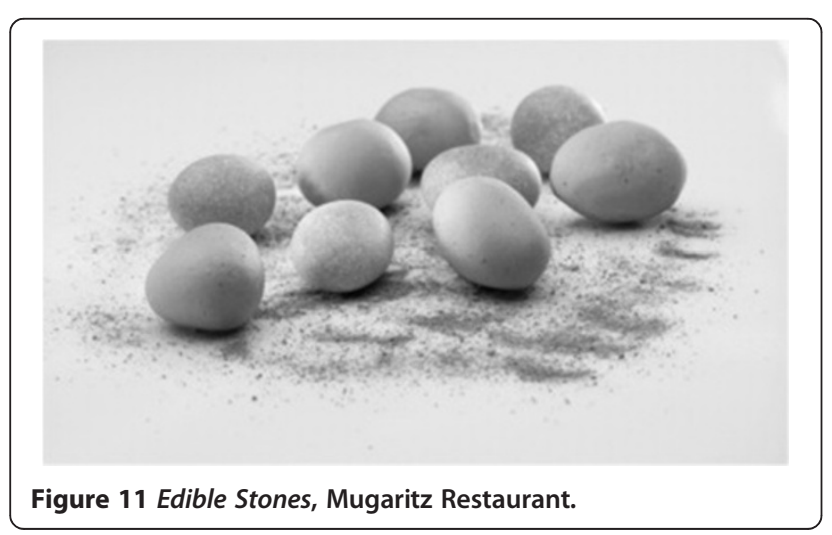

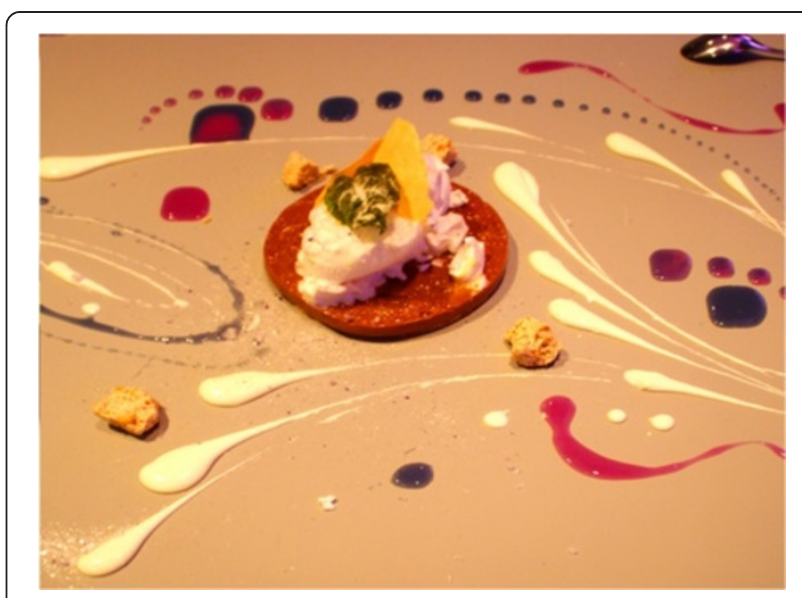

Figure 12 The final course served at Alinea is 'plated' on the table. (Reproduced by permission of Betina Piqueras-Fiszman).

restaurants, and in the new blending of art and food that we have reviewed here. However, the collaboration between chefs, scientists, psychologists and designers, also encouraged by these famous chefs, is still much focused on the preparation of food: Our eyes, minds and palates have now to turn to the plate and understand the many influences that serving can exert on the perception of a dish.

\section{Endnotes}

${ }^{a}$ More prosaically, the evolution of plating that took place can also be attributed to one really important technological innovation that transformed the kitchen after the Second World War, namely, the refrigerator! More products became available, of substantially higher quality, thus enriching the colour and variety of ingredients that the cook could obtain.

${ }^{b}$ If one looks at the top of the 2013 San Pellegrino 50 Best Restaurants list, one sees Joan Roca, René Redzepi, Massimo Bottura and Andoni Luis Aduriz (in the first four places, respectively). These chefs all worked in the kitchens of elBulli at some point in their career, indicating the importance of this restaurant on contemporary dining practice.

\footnotetext{
Competing interests

The authors declare that they have no competing interests.
}

\section{Authors' contributions}

$\mathrm{OD}, \mathrm{CM}, \mathrm{BPF}$ and CS contributed equally to the manuscript and approved the final version of the manuscript. $C M$ is the first chef in residence at the Crossmodal Research Laboratory.

\section{Acknowledgements}

OD wishes to thank the audience at the University of Toronto, the Royal Institution and La Triennale di Milano for their comments on earlier presentations of this work. OD and CS are funded by the AHRC grant 'Rethinking the Senses' within the Science in Culture theme. 


\section{Author details}

${ }^{1}$ Centre for the Study of the Senses, School of Advanced Study, Institute of Philosophy, University of London, Malet Street, WC1E 7HU London, UK. ${ }^{2}$ Department of Experimental Psychology, Crossmodal Research Laboratory, University of Oxford, South Parks Road, Oxford OX1 3UD, UK.

Received: 3 October 2013 Accepted: 11 March 2014

Published: 15 May 2014

\section{References}

1. Apicius: Cooking and Dining in Imperial Rome, 1st century AD; translated by J.D. Vehling. Chicago: University of Chicago Press; 1936.

2. Yang J: The Art of Food Presentation. [http://www.cravemag.com/features/ the-art-of-food-presentation/]

3. Hardy S: Creative Generalist Q\&A: Homaro Cantu. [http://creativegeneralist. com/2007/11/creative-generalist-qa-homaro-cantu/]

4. Spence C, Piqueras-Fiszman B: The multisensory packaging of beverages. In Food Packaging: Procedures, Management and Trends. Edited by Kontominas MG. New York: Nova Publishers, Hauppauge; 2013:187-233.

5. Meiselman HL: Dimensions of the Meal: The Science, Culture, Business, and art of Eating. Gaithersburg: Aspen Publishers; 2000

6. Gustafsson IB: Culinary arts and meal science - a new scientific research discipline. Food Serv Technol 1996, 4:9-20.

7. The Art of Plating. [www.theartofplating.com]

8. Kahneman D, Fredrickson BL, Schreiber CA, Redelmeier DA: When more pain is preferred to less: adding a better end. Psychol Sci 1993, 4:401-405.

9. Kahneman D, Diener E, Schwarz N: Well-Being: The Foundations of Hedonic Psychology. New York: Russell Sage Foundation; 2003.

10. Spence C, Levitan C, Shankar MU, Zampini M: Does food color influence taste and flavor perception in humans? Chemosensory Percept 2010, 3:68-84.

11. Imram N: The role of visual cues in consumer perception and acceptance of a food product. Nutr Food Sci 1999, 99:224-230.

12. Allen JS: The Omnivorous Mind: Our Evolving Relationship with Food. London: Harvard University Press; 2012.

13. Pollan M: The Omnivore's Dilemma: A Natural History of Four Meals. New York: Penguin Press; 2006.

14. Watson L: The Omnivorous Ape. New York: Coward, McCann, \& Geoghegan; 1971.

15. Visser M: The Rituals of Dinner: The Origins, Evolution, Eccentricities, and Meaning of Table Manners. London: Penguin Books; 1991.

16. Counihan CM, Van Esterik P (Eds): Food and Culture: A Reader. London: Routledge; 2013.

17. Oshima A, Cwiertka KJ: Yamazato: Kaiseki Recipes: Secrets of the Japanese Cuisine. Bruges: Stichting Kunstboak; 2006.

18. Tannahill R: Food in History. New York: Stein \& Day; 1973

19. Vincent-Cassy M: La première artification du culinaire à la fin du Moyen Âge. (The first artification of cooking in the late middle Ages). In L'Artification du culinaire. Edited by Cohen E, Csergo J. Paris: Publications de la Sorbonne; 2012:37-48.

20. Frascari M: Semiotica ab edendo (Taste in architecture). In Eating Architecture. Edited by Horowitz J, Singley P. Cambridge MA: MIT Press; 2004:191-203.

21. Escoffier A: A Guide to Modern Cookery. Cambridge: Cambridge University Press; 2013.

22. Les Recettes Originales De... (Book Series). Paris: Robert Laffont:1977-2002.

23. Oliver R: Art et magie de la cuisine [Art and magic in cooking]. Paris: Del Duca; 1955. Préface.

24. Fontanille J: A déguster des yeux. Notes sur la " mise en assiette », à propos de la cuisine de Michel Bras (To taste with the eyes. Notes on 'plating', Michel Bras' cuisine). In La diversité du sensible. Edited by Beyaert A. Pulim: Collection: Visible. Limoges; 2006.

25. Myhrvold N, Young C: Modernist Cuisine. The Art and Science of Cooking. La Vergne, TN: Ingram Publisher Services; 2011.

26. Piqueras-Fiszman B, Spence C: Sensory incongruity in the food and beverage sector: Art, science, and commercialization. Petits Propos Culinaires 2012, 95:74-118.

27. Bro Pedersen L: Creativity in gastronomy: exploring the connection between art and craft. In MSOCSC thesis. Copenhagen Business School, Department of Management, Politics and Philosophy; 2012. http:// studenttheses.cbs.dk/handle/10417/3198
28. Gagnaire's Spirit. [http://www.pierre-gagnaire.com/en\#/pg/esprit_gagnaire/1] 29. reikokaneko. [www.reikokaneko.co.uk]

30. Park MY: A History of How Food Is Plated, from Medieval Bread Bowls to Noma. [http://www.bonappetit.com/trends/article/a-history-of-how-food-isplated-from-medieval-bread-bowls-to-noma]

31. Multidisciplinary Design Group Working With Alinea. [http://www. crucialdetail.com]

32. London Restaurant Serving Food on a Brick. [http://john-salt.com]

33. Genette G: Palimpsests: Literature in the Second Degree. Lincoln, NE: University of Nebraska Press; 1997.

34. Verjus B: Michel Troisgros, Entretien. Omnivore Magazine 2012, 4

35. Aduriz AL, Vergara J, Lasa D, Oliva O, Perisé R: Culinary trompe-l'oeil: a new concept in coating. Int J Gastronomy Food Sci 2012, 1:70-77.

36. Blumenthal $\mathrm{H}$ : Further Adventures in Search of Perfection: Reinventing Kitchen Classics. London: Bloomsbury Publishing; 2007.

37. Blumenthal H: The Big Fat Duck Cookbook. London: Bloomsbury; 2008.

38. Adrià F, Blumenthal H, Keller T, McGee H: Statement on the 'new cookery'. [http://www.theguardian.com/uk/2006/dec/10/foodanddrink. obsfoodmonthly]

doi:10.1186/2044-7248-3-6

Cite this article as: Deroy et al:: The plating manifesto (I): from decoration to creation. Flavour 2014 3:6.

\section{Submit your next manuscript to BioMed Central and take full advantage of:}

- Convenient online submission

- Thorough peer review

- No space constraints or color figure charges

- Immediate publication on acceptance

- Inclusion in PubMed, CAS, Scopus and Google Scholar

- Research which is freely available for redistribution

Submit your manuscript at www.biomedcentral.com/submit
C Biomed Central 